\title{
COMPETENCIA PARA LA MODIFICACIÓN DE SENTENCIAS EXTRANJERAS DE MEDIDAS YA RECONOCIDAS EN ESPAÑA Y TRASCENCENCIA DE LA VALORACIÓN JUDICIAL DE TRADUCCIONES CONTRADICTORIAS, A PROPÓSITO DE LA SENTENCIA DE LA AP BARCELONA 10 ENERO 2020
}

\author{
JURISDICTION FOR THE MODIFICATION OF FOREIGN \\ JUDGMENT MEASURES ALREADY RECOGNIZED IN SPAIN \\ AND TRASCENDENCE OF THE JUDICIAL ASSESSMENT OF \\ CONTRADICTORY TRANSLATIONS, CONCERNING THE \\ JUDGMENT OF AP BARCELONA JANUARY 10, 2020
}

\author{
LuCAs ANDRÉs PÉRez MarTíN** \\ Profesor Contratado Doctor de Derecho internacional privado \\ Universidad de Las Palmas de Gran Canaria \\ ORCID ID: 0000-0001-6340-0528
}

Recibido: 16.12.2020 / Aceptado: 12.01.2021

DOI: https://doi.org/10.20318/cdt.2021.6013

\begin{abstract}
Resumen: En el presente trabajo analizamos diversos aspectos procesales de gran interés resueltos por la sentencia de la Audiencia Provincial de Barcelona 10 enero 2020. En primer lugar, la competencia para la modificación de una resolución judicial extranjera de medidas respecto a un menor, ya reconocida en España, en la que sigue ostentando competencia judicial internacional el lugar de residencia habitual del menor en aplicación de Convenio de La Haya de 1996 sobre responsabilidad parental y el Reglamento 4/2009. En segundo lugar, las exigencias de la consideración de la rebeldía establecidas en el Convenio bilateral entre Marruecos y España de 1997. Y, por último, y especialmente interesante por sus efectos, la valoración judicial de las traducciones contradictorias de las sentencias extranjeras.

Palabras clave: ejecución resolución extranjera, modificación de medidas, rebeldía, traducción contradictoria.

Abstract: In this paper we analyze various procedural aspects of great interest resolved by the sentence of the Provincial Court of Barcelona January 10, 2020. First, the competence for the modification of a foreign judicial resolution of measures regarding a minor, already recognized in Spain, in which the minor's place of habitual residence continues holding international jurisdiction in application of the 1996 Hague Convention on parental responsibility and the Regulations 4/2009. Secondly, the requirements for the consideration of rebellion contained in the Bilateral Agreement of 1997 between Morocco and Spain. And, finally, and especially interesting for its effects, the judicial assessment of the contradictory translations of foreign judgments.

Keywords: execution of foreign resolution, modification of measures, rebellion, contradictory translation.dolupta

*Este trabajo ha sido realizado en el marco del Proyecto de Investigación I+D+I: "Obstáculos a la movilidad de personas en los nuevos escenarios de la UE", financiado por el Ministerio de Economía y Competitividad, Dirección General de Investigación Científica y Técnica, con la referencia DER2017-86017-R.

**1ucas.perez@ulpgc.es
\end{abstract}


Sumario: I. Los hechos, divorcio consensual marroquí, modificación de medidas y traducciones contradictorias. II. Aspectos procesales, competencia de la modificación de medidas y rebeldía. 1. Competencia para la modificación de medidas ya reconocidas en España. 2. La rebeldía en el Convenio Bilateral España - Marruecos de 1997. III. La trascendencia de la interpretación de traducciones contradictorias. 1. La olvidada importancia de la traducción en el derecho internacional privado. 2. Traducción y valoración judicial. IV. Conclusiones.

\section{Los hechos, divorcio consensual marroquí, modificación de medidas y traducciones contra- dictorias}

1. Los hechos que motivan la presente resolución se inician con la solicitud de reconocimiento y ejecución de una sentencia marroquí de modificación de medidas el 1 de agosto de 2018, si bien tienen su verdadero origen con anterioridad. Los cónyuges parte en el proceso, con doble nacionalidad, española y marroquí según la resolución, viven cuando se inicia el procedimiento, en Tánger él y entre Barcelona y Tánger, según la temporada del año, ella. Tienen un hijo nacido en 1999 que vive en dicho momento con el padre en Tánger. Los litigantes están divorciados según Acta de Divorcio Consensual de 16 de mayo de 2013 celebrado ante los tribunales de la ciudad marroquí1. En dicho procedimiento acordaron la guarda del menor por parte de la madre y una cuantía por alimentos a favor del hijo a abonar por el padre ${ }^{2}$. En dicho momento los tres vivían en Barcelona, y el divorcio consensual se reconoció en España mediante proceso al efecto en 2016, inscribiéndose en el Registro Civil español.

2. En fecha que no acredita la sentencia, pero que debió acaecer durante el año 2016, el padre y el menor (en ese momento con entre 16 y 17 años), se desplazan a Tánger. El padre inicia un procedimiento de modificación de medidas en dicha ciudad, que finaliza mediante Sentencia de 2 de marzo de 2017, que otorga la guarda del hijo al padre y deja sin efecto los alimentos establecidos en sentencia de 2013. En fecha también indeterminada la madre inició en España un procedimiento penal por impago de pensiones y de ejecución de la entrega del menor. Presentada la demanda de reconocimiento y ejecución de la sentencia de marzo de 2017, dicho procedimiento se paralizó por prejudicialidad penal ${ }^{3}$.

3. Para centrar las situaciones conflictivas que protagonizan el presente trabajo señalaremos que una vez solicitado el reconocimiento y ejecución de la sentencia de modificación de medidas la demandada se opuso al exequatur impugnando la traducción jurada, que considera insuficiente. Por otro lado, alegó la aplicabilidad del artículo 46 de la Ley de Cooperación Jurídica Internacional ${ }^{4}$, impugnando el procedimiento por falta de competencia ya que, con nacionalidad española de ambos, afirmó que la competencia para la modificación de efectos de sentencia era exclusiva de los Tribunales españoles,

\footnotetext{
${ }^{1}$ El divorcio consensual regulado en la Mudawana marroquí permite a los cónyuges regular su crisis familiar según los acuerdos entre ambos, por lo que la propia resolución lo asimila en el antecedente de hecho primero a un convenio regulador. Una visión general del divorcio y sus distintos tipos en las leyes de familia de los países árabes se puede consultar en C. Ruíz-Almodóvar, "El divorcio en las leyes de familia de los países árabes", MEAH, Sección árabe-islam, 55, 2006, pp. 323-337. Se puede consultar una visión general del divorcio en el Código marroquí de familia, la Mudawana, y sus efectos en M. D. OrTíz VidAL, "El repudio en el Código de Familia de Marruecos y la aplicación del Derecho marroquí en la UE”, CDT, Vol. 6, 2014, № 2, pp. 201-244.

${ }^{2}$ Sobre la relación entre la tutela del padre y el derecho de Hadana y guarda de la madre en el Derecho privado islámico, vid. P. Mandirola Brieux, Introducción al Derecho Islámico, Madrid, Marcial Pons, 1998, p. 111.

${ }^{3}$ La cercanía entre España y Marruecos y la movilidad entre dos orillas provoca conflictos con resoluciones de distintos orígenes y jurisdicciones en no pocas ocasiones, en los que es protagonista la numerosa colonia marroquí en Cataluña. Muchos son los ejemplos, uno de ellos, por ejemplo, no el único que citaremos en este trabajo, se analiza en, C. CARRILLO LERMA, "Divorcio en España entre Cónyuges marroquíes: la sentencia de la Audiencia Provincial de Barcelona de 30 diciembre 2014", $C D T$, Vol. 7, 2015, № 2, pp. 413-419. Sobre la aplicación de la Mudawana, y su relación con el orden público español, tema de enorme interés, pero sobre el que no podemos detenernos por no ser objeto del presente trabajo, vid. M. D. CervilLa Garzón, "La aplicabilidad de las normas del Código de Familia marroquí (la Mudawana) que regulan el divorcio en España: el filtro constitucional", $C D T$, Vol. 10, 2018, № 1, pp. 144-163.

${ }^{4}$ Ley 29/2015, de 30 de julio, de cooperación jurídica internacional en materia civil, BOE núm. 182, de 31/07/2015 (en adelante LCJI). El artículo 46 recoge las causas de denegación del exequatur.
} 
denunciando también indefensión, negando haber comparecido ante el Tribunal marroquí y que se le notificara la sentencia en ningún momento. Por último, dio cuenta que existe procedimiento de ejecución de sentencia por impago de pensiones, y afirmó que la acción no era más que un fraude procesal para evitar el pago al que estaba obligado el padre.

4. El Auto de primera instancia recurrido, de fecha 22 de enero de 2019, admitió la ejecución, entendiendo que la sentencia marroquí cumple con los requisitos del art. 399 LEC y 54.4 y 46 de la Ley de Cooperación Jurídica Internacional y reconoció su eficacia civil, produciendo efectos de cosa juzgada desde la fecha de dicho Auto. En la apelación la demandada insistió en sus argumentos de primera instancia, añadiendo que la retroacción de los efectos económicos establecida en la sentencia marroquí es contraria a Derecho, refiriendo por ello infracción de orden público, lo que estudiaremos de forma monográfica en el último epígrafe del presente trabajo.

\section{Aspectos procesales, competencia de la modificación de medidas y rebeldía}

5. Con estos planteamientos nos centraremos en el presente epígrafe en los dos debates vinculados al origen del proceso y que preceden al aspecto de fondo que interrelaciona la traducción con el orden público y que estudiaremos en el siguiente epígrafe. En primer lugar, analizaremos las alegaciones de las partes respecto a la competencia judicial internacional del procedimiento de ejecución de medidas iniciado en 2017, al que se le aplican regímenes jurídicos variados por la naturaleza de la acción ejercitada. Tras ello debemos también estudiar la alegación de la madre respecto a la rebeldía en el que alega incurrió el procedimiento marroquí por no haberse personado en los autos, por la que pide la no ejecución de la sentencia.

\section{Competencia para la modificación de medidas ya reconocidas en España}

6. En primer lugar, la Sala considera no cuestionado por ninguna de las partes, ni lo hace ella misma, la competencia judicial española para el reconocimiento y la ejecución de la sentencia extranjera, toda vez que, como vimos en el relato de los hechos, la misma despliega indudables efectos en España y la resolución que modifica ya había sido reconocida en nuestro país ${ }^{5}$. El debate se centra en la competencia de la acción de modificación de medidas respecto al menor, ya que la madre alegó que para la acción de modificación de los efectos de la sentencia consensual de divorcio ya reconocida en España eran únicamente competentes los Tribunales españoles, con exclusión de los marroquíes, por la nacionalidad de las partes y porque la sentencia anterior ya estaba reconocida y desplegaba efectos en nuestro país. La demanda de modificación contiene dos acciones, la de la guarda y custodia del menor y la de la reclamación de alimentos, que estudiaremos por separado y posteriormente interrelacionaremos.

7. En relación a la acción relativa a la guarda y custodia, el momento en el que se produce la modificación de medidas con el divorcio ya consumado, el menor vivía en Tánger con su padre. La madre vivía de forma alternativa entre Tánger y Barcelona sin que de los datos de la resolución podamos derivar cuánto tiempo vivía en una y en otra y con qué propósito, y por lo tanto el lugar de concreción de su residencia habitual. En tales circunstancias, y sin residencia habitual ni del padre ni del hijo en España, el régimen jurídico aplicable a la determinación de la competencia judicial internacional a la acción de modificación de medidas sobre la guardia y custodia del menor sería el régimen interno si no existiese Convenio internacional firmado por las partes, toda vez que no es aplicable el régimen euro-

\footnotetext{
${ }^{5}$ La competencia para el reconocimiento y ejecución de las sentencias la tienen los tribunales españoles en aquellos asuntos que pueden desplegar efectos en el ordenamiento jurídico interno según lo regulado en los Reglamentos europeos que regulan la materia respecto a las resoluciones de Estados miembros de la Unión Europea y, respecto a sentencias de países terceros, como es el caso, por lo regulado en el Título V de la LCJI, artículos 41 a 61. Respecto a las resoluciones susceptibles de ejecución en España en materia civil y mercantil y sus efectos, desde una perspectiva general, vid. F.J. GarcimARTín AlFÉREZ, Derecho internacional privado, Cizur Menor, Aranzadi, quinta edición, 2019, pp. 247 a 249.
} 
peo $^{6}$. Pero dicho Convenio existe. El Convenio de La Haya de $1996^{7}$ relativo a la responsabilidad parental sobre medidas de los menores estaba vigente en el año 2017 tanto en España como en Marruecos ${ }^{8}$, y era el régimen aplicable a la competencia judicial de la acción por lo establecido en su artículo 3.b, que establece que se aplica a la responsabilidad parental, que incluye las decisiones sobre el ejercicio del derecho relativo al cuidado del niño y, en particular, el de decidir sobre su lugar de residencia, así como el derecho de visita. Esta era la primera acción ejercitada, la del derecho de custodia del menor como plasmación del ejercicio de la patria potestad. En dicho momento el Convenio le era aplicable al menor según lo dispuesto en su artículo 2, toda vez que aún no había cumplido los 18 años. El citado instrumento jurídico establece en su artículo 5.1 con total claridad que la competencia para el conocimiento de estas acciones es la del estado de la residencia habitual del niño ${ }^{9}$. E incluso, en caso de un cambio de residencia habitual, que aquí se había producido con anterioridad al inicio del procedimiento de modificación de medidas de España a Marruecos, le otorga la competencia también a las autoridades del estado de la nueva residencia habitual ${ }^{10}$. La Audiencia Provincial no citó este régimen jurídico para decidir sobre la falta de competencia, remitiéndose directamente al artículo 22 quater 3 de la LOPJ y al Reglamento de alimentos únicamente ${ }^{11}$. A nuestro juicio, esta falta de referencia al citado instrumento convencional supone un error, toda vez que la acción solicitaba el doble pronunciamiento, el de la modificación de la guarda y custodia y la cuantía vinculada al derecho de alimentos.

8. Por si esta regulación no fuese suficiente para negar la competencia exclusiva de los tribunales españoles respecto a esa acción, el artículo 45.1 de la Ley de Cooperación Jurídica internacional establece que una resolución extranjera podrá ser modificada por los órganos jurisdiccionales españoles siempre que hubiera obtenido previamente su reconocimiento por vía principal o incidental con arreglo a las disposiciones de este título ${ }^{12}$. Esta regulación faculta a la modificación de la resolución, añadimos nosotros, siempre que los tribunales españoles fuesen competentes según la normativa aplicable para ello, y otorga una competencia que faculta a los Tribunales españoles que puedan llevar a cabo dicha modificación, pero que en ningún caso les otorga una competencia judicial internacional exclusiva. Mucho menos en caso de que el menor, como ocurría en el presente supuesto, viviese fuera de España. El artículo ha sido criticado por la doctrina, que en dicho análisis expresamente ha señalado que dicha competencia en absoluto es exclusiva de España y que es concurrente con la competencia del país de origen de la resolución ${ }^{13}$. También, nuestro régimen jurídico interno ha regulado en el artículo 775 de la

${ }^{6}$ Ya se pronunció al respecto en un supuesto similar de un divorcio sirio el TJUE en su Auto 12 mayo 2016, asunto C-281/15, Caso Soha Sahyouni y Raja Mamisch, ECLI:EU:C:2016:343. En él un nacional doble nacional sirio y alemán solicitaba un reconocimiento de un divorcio privado sirio ante los tribunales alemanes, y el TJUE declaró no aplicable la regulación europea si la legislación alemana no se remitía a la europea, lo que no hacía. Tampoco el artículo 22 quater 3 de la LOPJ se remite expresamente ella. Al respecto, vid. C. CAAmiÑa Domínguez, "Divorcio privado dictado por un tribunal religioso de un tercero estado: asunto C-281/15 Soha Sahyouni y Raja Mamisch”, CDT, Vol. 9, 2017, N² 2, pp. 629-634.

${ }^{7}$ Convenio de 19 de octubre de 1996 Relativo a la Competencia, la Ley Aplicable, el Reconocimiento, la Ejecución y la Cooperación en materia de Responsabilidad Parental y de Medidas de Protección de los Niños, BOE núm. 291, 2 diciembre 2010,

${ }^{8}$ Convenio vigente en Marruecos a partir de 1 de diciembre de 2002 y en España a partir del 1 de enero de 2012, y aplicable para determinar la competencia judicial internacional en el presente supuesto. Respecto al estado actual del Convenio, vid. https://www.hcch.net/es/instruments/conventions/status-table/?cid=70.

${ }^{9}$ Un análisis detallado de distintos aspectos relacionados con esa residencia habitual y los foros relacionados con ella en el Convenio lo podemos ver en A.L. Calvo Caravaca y J. Carrascosa González, Derecho internacional privado Vol. II, Granada, Comares, decimoctava edición, 2018. pp. 455-459.

${ }^{10}$ Un excelente trabajo sobre la relación entre el Reglamento Bruselas II bis y el Convenio de La Haya de 1996 según lo dispuesto por el artículo 61 del Reglamento en los supuestos en los que los menores residen fuera de la Unión Europea, pero alguno de sus progenitores ejercientes de la patria potestad en un Estado miembro, lo podemos encontrar en, M. HERRÁNZ BALLESTEROS, "Competencia judicial internacional de las autoridades españolas sobre menores con residencia habitual en terceros Estados", en VArios Autores, El Derecho internacional privado entre la tradición y la innovación, libro homenaje al Prof. Dr. José María Espinar Vicente, Madrid, IPROLEX, 2020, pp. 401-410.

${ }^{11}$ El Convenio no es aplicable a los alimentos por la expresa exclusión de su ámbito de aplicación del artículo 4.e, por lo que al respecto sería de aplicación lo regulado en el Reglamento 4/2009, sobre lo que volveremos a continuación.

${ }^{12} \mathrm{Su}$ apartado segundo también da opción a la parte a plantear una nueva demanda en un procedimiento declarativo ante los órganos jurisdiccionales españoles

${ }^{13}$ Vid. J. M. Espinar Vicente y J. I. Paredes Pérez, “Análisis crítico del artículo 45 de la ley 19/2015: resoluciones extran- 
Ley de Enjuiciamiento Civil que tanto el Ministerio Fiscal como los cónyuges podrán instar del tribunal que acordó las medidas definitivas la modificación de las medidas convenidas por los cónyuges o de las adoptadas en defecto de acuerdo. Si bien el artículo ha recibido claras críticas al respecto de teóricos y prácticos del derecho ${ }^{14}$, nos lleva a la misma conclusión contraria a las alegaciones de la demandada, y toda vez que el tribunal que acordó las medidas no era español, y no había vinculación directa en ese momento del menor con España ${ }^{15}$, la competencia no es la española.

9. Sobre la acción de alimentos, argumenta erróneamente la sentencia analizada que artículo 3 del Reglamento 4/2009 de alimentos ${ }^{16}$ remite a la ley del foro para determinar el órgano judicial competente, y tras ello estudia el contenido del artículo 22 quater 3 para analizar la competencia española. El Reglamento de alimentos aplica sus normas independientemente del domicilio del demandado, con una vocación de plenitud, por lo que, en las reclamaciones de alimentos, las normas de competencia de la LOPJ deben quedar descartadas para el conocimiento del estado competente ${ }^{17}$. El artículo 3, lo que sí que hace en sus sucesivas letras, es establecer un régimen de foros alternativos plenamente disponibles para el demandante, fijados en el foro de la residencia habitual del demandado o del acreedor, o del que conozca la demanda principal a la que la reclamación de alimentos sea accesoria, que puede ser la demanda de responsabilidad parental, cuya competencia ya vimos en anteriormente que en este procedimiento era Marruecos. En ningún caso establece un foro exclusivo a favor del estado en el que una sentencia de alimentos extranjera hubiese sido ya reconocida. El Reglamento por supuesto no nos señala que Marruecos sea competente, lo que dependerá de la legislación procesal marroquí, pero lo que desde luego no regula en ningún caso es que España fuese competente en exclusiva, por no ser la residencia habitual del acreedor de alimentos y ser la residencia esporádica de la madre ${ }^{18}$.

10. Y de hecho, para acabar este análisis, podemos señalar que, si bien el Reglamento no es aplicable en Marruecos, como tampoco están vigentes en el país vecino ni el Convenio de La Haya de alimentos de 2007 ni el Protocolo de la misma fecha ${ }^{19}$, si estuviésemos ante el debate de la competencia entre dos tribunales europeos, lo que sí que hace el Reglamento en su artículo 8 es limitar las demandas sucesivas de revisión o modificación de los alimentos fijándolas al Estado miembro de la residencia del

jeras susceptibles de modificación”, AEDIPr, T XVII, 2017, pp. 507-531, p. 530. En su análisis exponen expresamente. que la sentencia, para poder ser modificable en España, antes debe serlo en el país de origen según sus normas procesales. Al respecto, también, vid, J. I. PARedes Pérez, "Reconocimiento y ejecución de pronunciamientos vinculados a la crisis matrimonial", M. Guzmán Zapater y M. Herranz Ballesteros (Directoras), Crisis matrimoniales internacionales y sus efectos. Derecho español y de la Unión Europea, Valencia, Tirant lo Blanch, 2018, 591-647.

${ }^{14}$ Sobre la visión más práctica vid. Y. Dutrey, ¿Cómo es la competencia judicial internacional en la modificación de medidas en materia de menores?, Confilegal, en https://confilegal.com/20170923-como-es-la-competencia-judicial-internacionalen-la-modificacion-de-medidas-en-materia-de-menores/.

${ }^{15}$ Un interesante estudio que analiza los criterios que pueden concretar la vinculación del menor, si bien en el nuevo Derecho europeo, lo podemos ver en M. A. SÁNCHEZ JiMÉNEZ, “Acción de responsabilidad parental vinculada a un proceso de divorcio en el nuevo Reglamento 2019/111", REDI, Vol. 72, 2020, № 1, pp. 143-162, pp. 155.159.

${ }^{16}$ Reglamento (CE) no 4/2009 del Consejo, de 18 de diciembre de 2008, relativo a la competencia, la ley aplicable, el reconocimiento y la ejecución de las resoluciones y la cooperación en materia de obligaciones de alimentos, DO L 7/1 de 10 de enero de 2009.

${ }^{17}$ Vid. M. GuZmán ZAPATER (directora), Lecciones de Derecho internacional privado, Valencia, Tirant lo Blanch, 2019, p. 455.

${ }^{18}$ Respecto a un caso resuelto por nuestro Tribunal Supremo en el que España sí era competente por ser el domicilio de la acreedora de alimentos, vid. M. J. VAlverde Martínez, "Competencia en la modificación por tribunales españoles de medidas relativas a alimentos establecidas por tribunales extranjeros. Comentario al Auto del Tribunal Supremo de 17 de septiembre de 2019”, CDT, Vol. 12, 2020, No 1, pp. 763-775. También resolvió en mismo sentido, estableciendo una competencia concurrente en un asunto similar en una modificación de medidas de una sentencia dictada en Estados Unidos, la STC 13 abril 2000 , ECLI:ES:TC:2000:61.

${ }^{19}$ Como la gran generalidad de los países en los que se aplica el derecho privado islámico, Marruecos no ha suscrito ni el Convenio de 23 de noviembre de 2007 sobre Cobro Internacional de Alimentos para los Niños y otros Miembros de la Familia (vid. https://www.hcch.net/es/instruments/conventions/status-table/?cid=131) ni el Protocolo de 23 de noviembre de 2007 sobre la Ley Aplicable a las Obligaciones Alimenticias (vid. https://www.hcch.net/index.cfm/es/instruments/conventions/statustable/?taal=es\&cid=133). 
acreedor si fue el que dictó la primera resolución y este aún sigue viviendo allí ${ }^{20}$, justo lo ocurrido en este supuesto respecto a Marruecos ${ }^{21}$.

\section{La rebeldía en el Convenio Bilateral España - Marruecos de 1997}

11. Alega la esposa en su oposición al reconocimiento de la resolución que la misma fue dictada en rebeldía, negando haber comparecido ante el tribunal marroquí y que se le notificara la sentencia. El régimen jurídico de la rebeldía alegado por la misma, el del artículo 46 de la Ley de Cooperación Judicial, no es el aplicable a este supuesto, ya que al respecto hay Convenio internacional con aplicación preferente a la misma, en concreto el Convenio de Cooperación Judicial en Materia Civil, Mercantil y Administrativa entre el Reino de España y el Reino de Marrue $\cos ^{22}$ que veremos a continuación. La denegación del reconocimiento de resoluciones dictadas en rebeldía tiene como fundamento la dimensión procesal del orden público, en la intención de proteger los derechos de defesa de las partes ${ }^{23}$, con las exigencias recogidas en nuestro ordenamiento jurídico tanto en la normativa interna como europea como convencional que han sido desarrolladas y concretadas por nuestros Tribunales ${ }^{24}$.

12. El Convenio hispano - marroquí, en sus artículos 22 y 23 exige que la sentencia de la que se solicita su reconocimiento para que logre la autoridad de cosa juzgada y fuerza ejecutiva en España cumpla varios requisitos, y entre otros ${ }^{25}$ exige que las partes hayan sido legalmente citadas, representadas o declaradas rebeldes. Así pues, el tribunal requerido puede analizar de oficio el correcto control de las garantías procesales de las partes en el procedimiento de origen, en este caso el de modificación de medidas resuelto por la sentencia de 2 de marzo de 2017, y en el caso de no cumplirse estas garantías no debe reconocer la resolución. Debe analizar si la parte ha sido adecuadamente citada, o si ha sido representada en el procedimiento, y en caso contrario si fue correctamente declarada rebelde. De hecho, la existencia de la vulneración de los derechos de defensa de las partes en procedimientos similares de divorcios marroquíes como el que estudiamos por su posible falta de notificación o emplazamiento ha sido alegada en anteriores ocasiones ante nuestros tribunales ${ }^{26}$.

${ }^{20}$ Vid. J.C. Fernández Rozas Y S. SÁnchez LoRenzo, Derecho internacional privado, Cizur Menor, Cívitas, décima edición, 2018, p. 528, con reflejo también de la jurisprudencia del TJUE que asienta este principio.

${ }^{21} \mathrm{Al}$ respecto de la interrelación entre los instrumentos que regulan la obligación de alimentos convencionales y de derecho europeo y la pluralidad y dispersión de estas normas, vid. A Borrás, "La reclamación internacional de alimentos: de La Haya a Bruselas”, en VARIOS AUTORES, Relaciones transfronterizas, globalización y Derecho, homenaje al Prof. Dr. José Carlos Fernández Rozas, Cizur Menor, Cívitas, 2020, pp. 129-144. En el día en el que se finaliza el presente trabajo, 15 de diciembre de 2020, se ha conocido la triste noticia del fallecimiento de la Profesora Borrás. Sirvan esas breves líneas de recuerdo y homenaje a su ingente labor investigadora, docente y al servicio de la evolución del Derecho Internacional Privado.

${ }^{22}$ Firmado en Madrid el 30 de mayo de 1997. BOE no 151 de 25 de junio de 1997 (en adelante Convenio hispano - marroquí). Hasta el momento no hemos estudiado el citado texto normativo toda vez que, siendo un Convenio de cooperación judicial, no tiene disposiciones concretas sobre la competencia judicial internacional, objeto de estudio del apartado primero de este epígrafe.

${ }^{23}$ Vid. A. Rodríguez Benot (director), Manual de Derecho internacional privado, Madrid, Tecnos, séptima edición, 2020, p. 122.

${ }^{24}$ Respecto al desarrollo de los requisitos para apreciar la rebeldía en el Tribunal Supremo, vid. A. RodríGuez BenOt, "Derecho de defensa y exequátur de resoluciones extranjeras en España en la Jurisprudencia del Tribunal Supremo", en A. L. CALVo Caravaca y J. Carrascosa González (directores), El Tribunal Supremo y el Derecho Internacional Privado, Vol. I, Murcia, Colección Derecho y Letras, 2019, pp. 33-46.

${ }^{25}$ Que la resolución emane de un órgano jurisdiccional competente según las normas aplicables en el país; que haya adquirido autoridad de cosa juzgada y haya llegado a ser ejecutiva conforme a las leyes del Estado en que haya sido dictada; que no contenga disposiciones contrarias al orden público español ni a los principios del derecho internacional, ni sea contraria a una resolución judicial dictada en España y que haya adquirido autoridad de cosa juzgada; y que no se encuentre pendiente ningún proceso entre las mismas partes y por el mismo objeto ante algún órgano jurisdiccional del Estado requerido.

${ }^{26}$ Dos supuestos recientes al analizado por nosotros pueden consultarse en; L. S. Heredia SáncheZ, "Procedencia de exequatur de Sentencia extranjera de divorcio dictada en rebeldía del demandado: comentario al Auto de la Audiencia Provincial de Tarragona, de 21 de enero de 2019" CDT, Vol. 11, 2019, № 1, pp. 636-640; y en M. Vargas Gómez-URrutia, "Exequatur de Sentencia marroquí - divorcio y alimentos: citación legal, firmeza y ejecución provisional (Audiencia provincial Girona, Auto de 08/10/2019), CDT, Vol. 12, 2020, Nº 2, pp. 1199-1206. 
13. Pues bien, así las cosas, la alegación de la rebeldía de la demandada en el actual proceso tiene ciertamente poco recorrido, toda vez que la propia sentencia marroquí de 2 marzo 2017 recoge expresamente que la demandada compareció y contestó la demanda. En las dos traducciones existentes en autos de la sentencia se recoge que la demandada compareció y estuvo defendida por el abogado Sr. Abdallah Bakhat, contestando a la demanda y ejerciendo lo que a su derecho convenía, sin que exista en el procedimiento ninguna referencia ni a la rebeldía efectiva ni a la rebeldía de conveniencia que alegó en la segunda instancia. Por todo lo referido, no existió en el proceso la rebeldía alegada, que le produjese indefensión alguna ${ }^{27}$, por lo que dicha alegación fue correctamente desestimada por ambas resoluciones.

\section{La trascendencia de la interpretación de traducciones contradictorias}

14. En el presente supuesto la traducción de la sentencia sobre la que se solicita el reconocimiento es esencial en el aspecto económico. El menor nació en 1999, por lo que a la fecha de la primera sentencia tenía 14 años y los efectos jurídicos sobre el mismo del divorcio consensual abarcaban las medidas de guarda y custodia y el derecho de alimentos. En el momento en el que se dicta la segunda sentencia, 2017, ese mismo año cumplía los 18 años, por lo que los efectos relativos a la guarda y custodia decaían por su llegada a la mayoría edad. Sin embargo, los efectos relativos a las cuantías económicas reconocidas como alimentos en favor del hijo y el momento en el que deben empezar a contabilizarse adquirían gran importancia. La traducción que aporta el padre de la resolución refleja que "declara improcedente los importes pronunciados a favor de la demandada como derechos relativos al hijo a contar de la fecha del divorcio de mutuo acuerdo el 11/04/2013". El mismo párrafo, según la traducción aportada por la madre reza "Se decreta que la demandada no tiene derecho a la percepción de las cantidades que se decretaron a favor del hijo y que comenzó a percibir desde la fecha efectiva del divorcio de la pareja, el 11-04-2013".

15. La diferencia entre una traducción y otra provocan una duda mayúscula que supondría gran diferencia en el reconocimiento de los derechos de las partes según cómo se resuelva. En la primera se expone que son improcedentes los ingresos recibidos por la madre, a contar desde el momento de la sentencia de divorcio consensual. Si son improcedentes a contar desde dicha fecha se pude interpretar directamente que debe devolverlos, provocando un débito inmediato a favor del padre. Si como dice la segunda traducción la esposa no tiene derecho a recibir la cuantía por alimentos a favor del hijo que empezó a recibir desde aquel momento, esto solo significa que dejará de recibirlos en adelante, sin efecto retroactivo alguno. Con ambas traducciones estaríamos ante efectos diametralmente diferentes respecto a las obligaciones económicas de la madre a partir de dicho momento.

\section{La olvidada importancia de la traducción en el derecho procesal civil internacional}

16. Al respecto debemos destacar brevemente que, en el Derecho internacional privado, y en concreto en el reconocimiento y ejecución de resoluciones con importantes efectos prácticos de derecho material, el contenido textual de las resoluciones que inicialmente están redactadas en el idioma del estado que las emitió es básico. Por ello la traducción cobra una importancia crucial en el reconocimiento del derecho de los ciudadanos. Un cambio de una palabra que en cualquier otro contexto, además de admitida, no tendría mayores consecuencias, en nuestra disciplina cambia el resultado final de un proceso

\footnotetext{
${ }^{27}$ Un detenido e interesante estudio sobre la posible flexibilidad de la apreciación de dichos requisitos huyendo de excesivos formalismos en la LCJI la aporta C. I. CoRDERo ÁlvAREZ, "La rebeldía del demandado en el control de las garantías procesales como causa de denegación del reconocimiento en la Ley de cooperación jurídica internacional: una visión comparada con el sistema Bruselas", REEI, No 32, 2016, pp. 1-38.
} 
que ha durado años ${ }^{28}$, tal y como ocurre en el presente supuesto ${ }^{29}$. Es una impresión personal de quien ha ejercido función jurisdiccional anteriormente el hecho de que la traducción, usualmente, se ha considerado como un trámite más que se debe cumplir y sobre el que no siempre se presta la atención suficiente. Vista en ocasiones como un coste más del proceso, múltiples son los aspectos que afectan a la traducción y que no siempre son valorados, como su origen y la cualificación del traductor, la terminología empleada por la misma o su formalización, siendo muy habituales las expresiones de derecho positivo que recojan que un determinado documento debe estar "debidamente traducido" o por el "órgano o funcionario competente", o por "persona cualificada", lo que no deja claramente acreditado si el legislador exige para cada momento la traducción jurada, oficial o de cualquier persona con conocimiento en lenguas ${ }^{30}$.

17. En concreto, en lo relativo a las traducciones del árabe, adquiere especial dificultad en varios tipos de acciones que se pueden iniciar en el derecho de familia. Por ejemplo, en los procedimientos de exequatur en materia de divorcio, toda vez que en árabe se multiplican las palabras para designar conceptos que en español se conocen todos ellos únicamente como divorcio, lo que provoca la necesidad de una concreción que en ocasiones no es factible y requiere una adaptación a nuestro ordenamiento jurídico $^{31}$. Este hecho ocurre con los distintos tipos de divorcio existentes, antes de la consumación, de mutuo acuerdo, el repudio o el divorcio judicial. Y también se interrelaciona con las circunstancias y responsabilidades en la forma de inicio de activación de una institución no especialmente bien vista por el Derecho privado islámico, que conlleva mayores o menores costes económicos y medidas finales según la responsabilidad de los cónyuges en el divorcio ${ }^{32}$, lo que provoca claros conflictos de adaptación entre el derecho islámico y el occidental ${ }^{33}$.

\section{Traducción y valoración judicial}

18. Asentada esta prevención, estimamos que la Audiencia Provincial realiza un correcto análisis y valoración de las traducciones aportadas por las partes. Entre el término "a contar" de la traducción aportada por el padre y "que comenzó a percibir" aportada por la madre, el Tribunal estimó que aplican-

\footnotetext{
${ }^{28}$ Estudia aspectos generales de la interpretación en el Derecho internacional privado y en concreto las reformas de organización de la traducción e interpretación oficial de la LCJI, A. LARA AguAdo, "La reforma de la traducción e interpretación oficial en el Derecho internacional privado español”, REEI, No 32, 2016, pp. 1-36. En el trabajo expone la inmensa cantidad de trámites de DIPr que requieren la traducción previa de documentos de gran importancia.

${ }^{29}$ Amplía información sobre el marco jurídico de la traducción e interpretación institucional, desde la perspectiva regulatoria y la práctica, el Libro blanco de la traducción y de la interpretación institucional, Ministerio de Asuntos Exteriores y Cooperación, 2001, disponible en; http://www.ritap.es/wp-content/uploads/2012/11/libro_blanco_traduccion_vfinal_es.pdf.

${ }^{30}$ Vid A. Lara Aguado, "La reforma de la traducción...", op. cit., p. 35. Las diferencias de requisitos y efectos legales entre las distintas traducciones es mucha y no siempre se advierten. Las traducciones certificadas por la Oficina de Interpretación de lenguas del Ministerio de Asuntos Exteriores, Unión Europea y Cooperación, las traducciones realizadas o asumidas como propias por las representaciones diplomáticas o consulares españolas en el extranjero o extranjeras en España, los traductores-intérpretes jurados, o quienes ejercen la función sin los mismos requisitos como traductores privados, son todos tipos diferentes de traducciones que conviven en la realidad diaria de nuestra actividad jurídica y judicial, toda vez que pocas disposiciones normativas exigen que las traducciones aportadas a los procesos sean oficiales o certificadas por personas autorizadas a tal fin.

${ }^{31}$ Precisamente centrado en la temática del presente trabajo, lo que denota la complejidad de la materia, vid. M. ELMadKoUR MAATAOUI, "La traducción del árabe al español y el execuátur en materia de divorcio", Anaquel Estudios Árabes, no 39, 2019, pp. 183-209.

${ }^{32}$ El artículo 84 de la Mudawana, respecto a las consecuencias del matrimonio establece que "Los derechos económicos debidos a la esposa implican la dote aplazada, cuando proceda, la manutención (nafaqa) debida durante el período legal de continencia (cidda) y la indemnización por la disolución del matrimonio por talaq (mutca), que se determinará en atención a la duración del matrimonio, la situación económica del esposo, los motivos de la disolución del matrimonio por talaq y el grado de abuso demostrado por el esposo al solicitar dicha disolución”. Este último criterio acredita lo señalado anteriormente Al respecto de esa adaptación de la institución de la disolución del matrimonio, vid. M. D. ORTIZ VIDaL, "El repudio en el Código de Familia de Marruecos...", op. cit., pp. 207-214.

${ }^{33}$ Tal y como recogió en su ya clásico trabajo, P. Diago Diago, "El islam en Europa y los conflictos ocultos en el ámbito familiar", REEI, No. 30, 2015, No 2, pp. 1--29.
} 
do los criterios sistemático, lógico y legal procedía darle mayor veracidad al término "que comenzó a percibir", y la falta de retroactividad de los efectos de la sentencia de modificación de medidas. El criterio sistemático porque en el resto de la resolución no se hace ninguna referencia expresa a la retroactividad de lo debido. El lógico porque es más razonable entender que la sentencia declara que no se deben seguir abonando alimentos, sin efectos retroactivos respecto a unas obligaciones jurídicas ya acordadas por las partes y aprobadas por el juzgador. Y por último por el legal por dos motivos. El primero, porque la sentencia no puede ser interpretada vulnerando el orden público español, que en el establecimiento del derecho de alimentos para el menor establece que el interés más necesitado de interés es el interés superior de este, y que exige que no se puedan considerar indebidas las cuantías de alimentos abonadas para su sustento cuando era menor de edad, desde los 14 a los 17 años $^{34}$. El segundo, porque en tal caso esta interpretación revocaría los efectos de cosa juzgada del primer procedimiento de reconocimiento de la sentencia de divorcio consensual ya vigentes y efectivos en nuestro país ${ }^{35}$.

\section{Conclusiones}

19. A tenor de lo establecido en el Convenio de La Haya de 1996 relativo a la responsabilidad parental sobre medidas de los menores, la competencia judicial para conocer una acción de modificación de una resolución marroquí, país firmante del Convenio, ya reconocida y ejecutada en España, no es una competencia exclusiva de los Tribunales españoles, por mucho que los efectos de esta modificación sean aplicados únicamente en nuestro país. Todo lo contrario, si el menor reside, como en el supuesto que analizamos, en Marruecos, la competencia judicial internacional de la misma la sigue manteniendo los Tribunales marroquíes que dictaron la primera resolución. Todo ello sin perjuicio de que, si el menor no estuviese residiendo en un Estado firmante del Convenio y alguno de los progenitores residiese en la Unión Europea, pudiesen aplicarse las normas del Reglamento Bruselas II bis para determinar la competencia concurrente del Estado miembro, en aplicación de su artículo 61.

20. La traducción de las sentencias y documentos públicos extranjeros redactados en el idioma del país de origen es un trámite procesal al que en ocasiones no se le da la importancia que tiene, y que está directamente vinculada al reconocimiento y disfrute de sus derechos por los ciudadanos. En el caso de la ruptura del contrato matrimonial en un país en el que se aplica el Derecho islámico, las distintas palabras árabes que describen diferentes tipos de disoluciones del matrimonio que en España confluyen todas en una única palabra, divorcio, pueden provocar una dificultad de adaptación de los efectos de la resolución extranjera y con ello un reconocimiento diferente al que procedería. En el supuesto analizado, la diferencia entre las distintas traducciones de la sentencia de la que solicita el reconocimiento aportadas por las partes podía suponer la aplicación retroactiva o no de la sentencia y con ello la posible obligación de devolver lo ya recibido en concepto de alimentos del hijo menor de edad. La aportada por el padre establecía la improcedencia de continuar con el pago de alimentos, "a contar" desde una fecha, la aportada por la madre "que se comenzaron a percibir" en esa fecha. Acertadamente el Tribunal empleó los criterios sistemático, lógico y legal para darle más valor al término "que se comenzaron a percibir", y con ello no establecer efectos retroactivos a la sentencia reconocida.

\footnotetext{
${ }^{34}$ Sobre la prestación de alimentos y el interés superior del menor, vid. C. DE AmunÁtEGUI Rodríguez, "La obligación de alimentar a los hijos menores y la limitación temporal de la misma por aplicación de lo dispuesto en el párrafo primero del artículo 148 del CC", Derecho Privado y Constitucional, N 29, 2015, pp. 11-45.

${ }^{35}$ El Tribunal no le otorga efectos retroactivos y de posible reclamación de los alimentos ya abonados al padre respecto a la madre, lo que como señala vulneraría le orden público español y los derechos del menor. Eso sí, en el conflicto abierto entre los padres, con procedimiento penal incluido por la falta de pago de los alimentos, señala en el Fundamento Jurídico tercero, que todo ello sin perjuicio de que el padre pueda alegar abuso de Derecho en la ejecución de sentencia que ha promovido la madre por impago de alimentos (suspendida por prejudicialidad civil, a la espera de la finalización del procedimiento que aquí analizamos), y en la que reclamó periodos en los que el menor vivía con el padre, o incluso, al amparo del artículo 28 del Convenio bilateral con Marruecos ya citado, oponer los efectos de cosa juzgada de esta resolución de reconocimiento de la sentencia de modificación de medidas de 2017 respecto a la reclamación de cantidades posteriores a dicha fecha la sentencia de modificación.
} 